\title{
ON THE POLYMORPHISM OF CYANOGENESIS IN LOTUS CORNICULATUS L.
}

\author{
VI. ECOLOGICAL STUDIES IN THE NETHERLANDS
}

\author{
W. M. ELLIS, R. J. KEYMER and DAVID A. JONES \\ Unit of Genetics, University of Hull, Hull HU6 7RX
}

Received 24.x.75

\begin{abstract}
SUMMARY
Ecological studies on the cyanogenic form of Lotus corniculatus $\mathrm{L}$. on the high dunes of West Holland do not support the hypothesis that grazing by rabbits is an important factor in the maintenance of the cline.
\end{abstract}

\section{INTRODUGTION}

ON the high coastal dunes of the Netherlands the frequency of the cyanogenic form of Lotus corniculatus L. shows a decrease from approximately 80 per cent to 20 per cent over the $5 \mathrm{~km}$ between Wassenaar and Katwijk (Jones, 1972). The distribution of cyanogenic forms of $L$. corniculatus has been associated with selective grazing (Jones, 1962, 1966; Crawford-Sidebotham, 1972), soil moisture (Foulds and Grime, 1972) and possibly with temperature (Jones, 1970 and in prep.). An analysis of the available climatological records showed that temperatures have been remarkably uniform along the whole coast and no correlation between frequency of cyanogenic plants and rainfall could be found, whereas circumstantial evidence indicated that grazing by rabbits could be an important factor. Jones (1972) suggested that further studies of the plants and the habitats between Wassenaar and Katwijk be carried out to determine the particular habitat factors which influence the cline. It is the purpose of this report to present the results of further work on the high dunes to the west of Leiden.

\section{Materials, methods AND Results}

The stuy area is approximately $5 \mathrm{~km}$ from south to north and $2 \mathrm{~km}$ from west to east. Twenty samples, each of at least 50 individual plants, were collected from this area in 1974 and tested for cyanogenesis. The methods of testing leaves for cyanogenesis have been given in detail elsewhere (Jones, 1966). Only plants scoring ++ for the presence of cyano-glucosides with $\beta$-glucosidase are cyanogenic. South of the road, from Wassenaar to the Paviljoen on the dunes, about 80 per cent of plants are cyanogenic and their frequency gradually decreases northwards to Katwijk where only 14 per cent of the plants are cyanogenic (fig. 1).

Having thus confirmed that the cline occurs over those $5 \mathrm{~km}$, a " Lotusindependent" ecological study of the area was carried out. Using the Wassenaarse Slag Road as a base line, two transects were laid down northwards parallel to the coast, one less than $500 \mathrm{~m}$ from the beach (coast) and the other (inland) more than $1 \mathrm{~km}$ from the beach. At $200 \mathrm{~m}$ intervals along 
each transect, $4 \mathrm{~m} \times 4 \mathrm{~m}$ quadrats were sampled, the quadrat size being large in relation to the size of the plants composing the vegetation (Lambert and Williams, 1962). Soil $p \mathrm{H}$ and conductivity were measured on three samples of soil per quadrat each diluted with 2.5 volumes of deionised water to 1 volume of soil. The samples were taken from just below the surface where $L$. corniculatus plants are rooted. Plant height was measured to the nearest $5 \mathrm{~cm}$ at 25 points on a grid laid out at $1 \mathrm{~m}$ intervals in each quadrat. The number of zero recordings was used as a measure of bare ground. All species present in a quadrat were recorded.

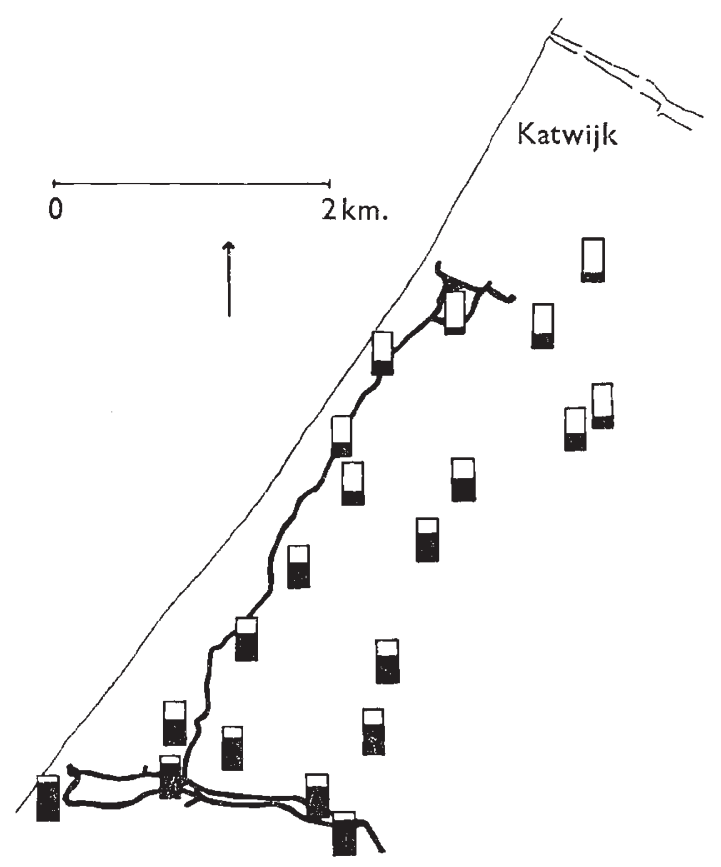

Wassenaar

FIg. 1.-The frequency distribution of the cyanogenic form of Lotus corniculatus between Wassenaar and Katwijk. The solid histograms represent the per cent ++ plants scored in each sample. The dark lines represent public footpaths.

The appropriate statistical techniques to evaluate changes from south to north on the transects were used, that is regression analyses on the quantitative data and association analyses on the categorical data. Differences between transects were estimated by analyses of variance.

The means and linear regression coefficients and their probability values (from $t$-tests) of the individual variables (table 1 ) show that, apart from the significant regression of the frequency of cyanogenic plants on distance north, no other variable gave a consistant regression in both transects. It is not possible, therefore, to explain the cline in terms of one of the variables which we measured during this study. We then used multiple regression analyses 
to find the best equations for two to five variables which could explain the relationship between distance north and frequency of cyanogenic plants. The calculations were done by ICL 1900 computer using the ICL Statistical Package program for multiple regression on a correlation matrix. The regression coefficients and $t$ statistics for the variables in each equation, the multiple correlation $\left(R^{2}\right)$ which indicates the percentage of the variation explained by the regression equation, and the intercept term and the Durbin-Watson $d$ statistic are shown in table 2 . The best regression equations with two variables in the set were formed from $p \mathrm{H}$ and species number for both transects. Because all the variables were significantly correlated with one another, addition of more variables to the equations explained only 5 to 10 per cent more of the variation.

\section{TABLE 1}

Means, regression coefficients and their probability values from $\mathrm{t}$-iests for linear regressions of individual variables against distance north of the Wassenaarse Slag Road on each transect

\begin{tabular}{|c|c|c|c|c|c|c|}
\hline \multirow[b]{2}{*}{ Variable } & \multicolumn{3}{|c|}{ Coast transect } & \multicolumn{3}{|c|}{ Inland transect } \\
\hline & Mean & $r$ & $P$ & Mean & $r$ & $P$ \\
\hline Frequency of ++ plants $\dagger$ & $37 \cdot 32$ & -0.68 & $<0.01 * *$ & $45 \cdot 82$ & $-0 \cdot 56$ & $<0 \cdot 02 *$ \\
\hline bH & $7 \cdot 99$ & 0.02 & $0 \cdot 1$ & $7 \cdot 57$ & $0 \cdot 08$ & $<0.01 * *$ \\
\hline Conductivity $\mu$ hmos & $72 \cdot 60$ & $-2 \cdot 15$ & $0 \cdot 2$ & $37 \cdot 70$ & $0 \cdot 17$ & $0 \cdot 6$ \\
\hline Plant height $\mathrm{cm}$ & $14 \cdot 72$ & -0.33 & $0 \cdot 1$ & $26 \cdot 03$ & -0.73 & $0 \cdot 1$ \\
\hline Per cent bare ground $\dagger$ & $28 \cdot 23$ & $0 \cdot 05$ & $0 \cdot 9$ & $20 \cdot 56$ & $0 \cdot 62$ & $<0.05^{*}$ \\
\hline Species number & $15 \cdot 75$ & 0.08 & $0 \cdot 5$ & $18 \cdot 05$ & $-0 \cdot 14$ & $0 \cdot 1$ \\
\hline
\end{tabular}

$\dagger$ Angular transformation of the frequency data was used.

The null hypothesis is that the results fit the linear model and may be rejected or accepted according to the value of the $d$ statistic. The distribution of $d$ depends on the correlation structure of the regressors (Huang, 1970) and if the value is less than the lower limit the null hypothesis must be rejected, if above the upper limit it may be accepted. If $d$ falls between the lower and upper limits the test is inconclusive. The significant points of $d_{L}$ and $d_{U}$ at the 5 per cent level are shown in table 3 . Clearly none of the regression equations can explain the cline, although the one for the inland transect using all five variables does approach an acceptable level of explanation.

The differences between the two transects, as measured by analyses of variance, were not significant (table 4). Therefore, none of the quantitative data we obtained gives a satisfactory explanation of the cline.

The categorical data of species composition of the quadrats were analysed by normal and inverse association analyses. In normal association analysis all differences relating to differences in abundance are eliminated and differences of richness remain; in inverse analysis richness is eliminated and differences in abundance remain. Both these analyses can then be amalgamated into a nodal analysis (Lambert and Williams, 1962) by the construction of a two-way table from which coincidence parameters are obtained and used to form noda and subnoda, basic vegetation units. In this instance the analysis was only carried as far as the two-way table, which Shimwell (1971) suggests " in many ways is a satisfactory end-point to the analysis ...". The 
two-way table * shows a mosaic pattern in the vegetation and does not indicate clinal variation. Rearranging the elements in the table in no way improves the clarity of the interpretation.

TABLE 2

Results of multiple regression analyses for two to five variables for both transects

\begin{tabular}{|c|c|c|c|c|c|c|}
\hline $\begin{array}{l}\text { Number of } \\
\text { variables }\end{array}$ & Variables & $\begin{array}{l}\text { Regression } \\
\text { coefficients }\end{array}$ & $t$ statistic & $R^{2}$ & $\begin{array}{l}\text { Intercept } \\
\text { term }\end{array}$ & $d$ statistic \\
\hline Coast transec & & & & & & \\
\hline 2 & $p \mathrm{H}$ & $0 \cdot 61$ & $2 \cdot 74$ & $33 \cdot 18$ & $2087 \cdot 16$ & $0 \cdot 83$ \\
\hline & Species number & $0 \cdot 47$ & $2 \cdot 11$ & - & - & - \\
\hline 3 & $p \mathrm{H}$ & 0.53 & $2 \cdot 29$ & $38 \cdot 32$ & $2093 \cdot 64$ & $0 \cdot 83$ \\
\hline & Species number & $0 \cdot 35$ & $1 \cdot 41$ & - & - & - \\
\hline & Plant height & $0 \cdot 25$ & $1 \cdot 16$ & & - & - \\
\hline 4 & $p \mathrm{H}$ & $0 \cdot 49$ & $1 \cdot 72$ & $38 \cdot 56$ & $2094 \cdot 05$ & $0 \cdot 89$ \\
\hline & Species number & $0 \cdot 34$ & $1 \cdot 35$ & - & - & - \\
\hline & Plant height & $0 \cdot 25$ & $1 \cdot 12$ & - & - & - \\
\hline & Conductivity & $0 \cdot 06$ & $0 \cdot 23$ & - & - & - \\
\hline 5 & $p \mathrm{H}$ & $0 \cdot 47$ & 1.53 & $38 \cdot 94$ & $2099 \cdot 24$ & $0 \cdot 85$ \\
\hline & Species number & $0 \cdot 26$ & $0 \cdot 68$ & - & - & - \\
\hline & Plant height & $0 \cdot 31$ & 0.99 & - & - & 一 \\
\hline & Conductivity & $0 \cdot 08$ & $0 \cdot 29$ & - & - & - \\
\hline & Per cent bare ground & $0 \cdot 10$ & $0 \cdot 28$ & - & - & - \\
\hline Inland trans & & & & & & \\
\hline 2 & $p \mathrm{H}$ & 0.65 & $4 \cdot 31$ & $62 \cdot 09$ & $2201 \cdot 67$ & $1 \cdot 29$ \\
\hline & Species number & $0 \cdot 37$ & $2 \cdot 41$ & - & - & - \\
\hline 3 & $p \mathrm{H}$ & $0 \cdot 63$ & $4 \cdot 42$ & $68 \cdot 89$ & $2203 \cdot 59$ & 1.57 \\
\hline & Species number & $0 \cdot 46$ & $3 \cdot 07$ & - & - & - \\
\hline & Conductivity & $0 \cdot 28$ & 1.88 & - & - & - \\
\hline 4 & $p \mathrm{H}$ & $0 \cdot 82$ & 3.91 & $71 \cdot 91$ & $2208 \cdot 62$ & $1 \cdot 79$ \\
\hline & Species number & 0.51 & $3 \cdot 35$ & - & - & - \\
\hline & Conductivity & $0 \cdot 31$ & $2 \cdot 10$ & - & - & - \\
\hline & Per cent bare ground & $0 \cdot 27$ & $1 \cdot 26$ & - & 一 & - \\
\hline 5 & $p \mathrm{H}$ & 0.83 & $3 \cdot 87$ & $72 \cdot 08$ & $2207 \cdot 19$ & $1 \cdot 88$ \\
\hline & Species number & 0.54 & $3 \cdot 05$ & - & - & - \\
\hline & Conductivity & $0 \cdot 33$ & $2 \cdot 07$ & - & - & - \\
\hline & Per cent bare ground & $0 \cdot 25$ & $1 \cdot 14$ & - & - & - \\
\hline & Plant height & $0 \cdot 06$ & $0 \cdot 36$ & - & - & - \\
\hline
\end{tabular}

\section{Discussion}

In ecological genetic studies, such as this, any final hypothesis is likely to depend on an overall knowledge of the particular habitat under study because we are investigating a multivariate situation. Our method of approach

* The computer outputs, the normal and inverse association analyses and the two-way table have been filed for reference in the Brynmor Jones Library, University of Hull; the John Crerar Library, 35 West 33rd Street, Chicago, Illinois, 60616 U.S.A. and the British Library, Lending Division, Boston Spa, Wetherby, W. Yorkshire, LS23 7BQ U.K. 
involves an ecological survey of a range of environmental factors, some of which are known to be selective agents in certain circumstances and our aim is to obtain ecological data which might indicate more precisely the role of these agents and also the direction of further research.

Of the three selective agents nominated as affecting the polymorphism of cyanogenesis in L. corniculatus (Jones, 1966, 1970, 1972 ; CrawfordSidebotham, 1972; Foulds and Grime, 1972) it is unlikely that temperature, soil moisture or rabbit grazing has any influence on the cline on the high dunes in the Netherlands. Temperatures and rainfall are essentially uniform

TABLE 3

The significant points of the Durbin-Watson d statistic for 20 samples at the 5 per cent level

$\begin{array}{ccc}\text { Number of variables } & d_{L} & d_{U} \\ 2 & 1.10 & 1.54 \\ 3 & 1.00 & 1.68 \\ 4 & 0.90 & 1.83 \\ 5 & 0.79 & 1.99\end{array}$

along the whole coast (Jones, 1972) and, although rabbit activity was not measured directly, there was no decline in pellet numbers seen towards Katwijk. The only significant changes we noted in any factors over this area occurred west to east, there being an increase in the age of the sand dunes and a decrease in recreational pressure.

TABLE 4

Analyses of variance between the two transects for the five variables measured and the frequency of cyanogenic plants

\begin{tabular}{llrrc}
\multicolumn{1}{c}{ Variable } & Source & d.f. & M.S. & $P$ \\
Frequency of ++ plants & Between & 1 & 269.64 & 0.2 \\
& Residual & 13 & 106.75 & - \\
pH & Between & 1 & 1.76 & 0.2 \\
Cesidual & 38 & 1.44 & - \\
Conductivity & Between & 1 & 12180.10 & $>0.05$ \\
Plant height & Residual & 38 & 3531.24 & - \\
& Between & 1 & 1279.16 & $>0.05$ \\
Per cent bare ground & Residual & 38 & 330.72 & - \\
& Between & 1 & 587.06 & $>0.05$ \\
Species number & Residual & 38 & 219.70 & - \\
& Between & 1 & 52.90 & $>0.05$
\end{tabular}

Our analyses of the habitat variation between Wassenaar and Katwijk were necessarily based on the linear model represented by the cline in cyanogenesis. None of the variation measured can, however, be satisfactorily explained in linear terms. The inland transect regressions of quantitative variables explained more of the variation than those of the coast transect and they approached significance at the 5 per cent level (tables 2 and 3). There were no significant differences between the transects (table 4) so it may be possible to extrapolate from one to the other when interpreting the results. The two variables which gave the best regression equation were $p \mathrm{H}$ and species number for both transects. Certainly the soil $p \mathrm{H}$ does vary, the range being 4.14 to 9.47 on the inland transect and 6.73 to 8.79 on the 
coast. These results demonstrate the value of two transects; interpretation of the inland transect must be tempered by the less significant differences on the coast transect. Not one of the multiple regression equations was significant and the maximum clinal variation which could be explained by these regressions was 72 per cent (table 2 ).

The association analyses of species abundance and diversity clearly do not fit the linear model either. They show the heterogeneity of the area both from south to north and between the transects. That the area is grazed by rabbits may affect the species composition. Among the most abundant species, Rubus sp., Hippophae rhamnoides, Rosa sp., and Carex arenaria could be classed as "rabbit avoided" and Festuca rubra, Erodium cicutarium, Lotus corniculatus and mosses such as Ceratodon pupureus, Hypnum cuppressiforme, Tortula ruraliformis and Dicranum scoparium as "rabbit resistant" following the system used by Gillham (1955). These classifications would vary depending on grazing pressure and there does not appear to be any regular pattern in the vegetation which would indicate differential or selective grazing.

From the circumstantial evidence that rabbits were rare at Katwijk and common at Wassenaarse Slag in 1971, Jones (1972) suggested that these animals could be playing a part in maintaining the polymorphism. Unfortunately he did not have any evidence about the distribution of rabbits between Katwijk and Wassenaarse Slag and thus we have no means of knowing whether the distribution of rabbits has changed since 1971, but subjectively it appears that rabbits were commoner near Katwijk in 1974. On the other hand the frequency of cyanogenic plants has not changed at either of the Katwijk or Wassenaar locations previously tested. Consequently selective grazing by rabbits seems less likely to be of importance in maintaining the cline than was thought hitherto.

Because neither the quantitative nor the categorical data fit the linear model we can have more confidence in proposing that the habitat is better represented by a heterogeneous mosaic on a smaller scale than the cline under investigation. This implies that the factors which affect the cline must be on a scale larger than the variables measured. For example, the position of the cline may be due to introgression on a latitudinal basis and the position may be moving north or south on a time span longer than the 3 years it has been studied.

It is clear that further study of the area is necessary, but it does not warrant intensive annual surveys. A 3-yearly cycle will probably be sufficient to detect any marked changes in the frequency of cyanogenic plants.

Acknowledgment.-We are most grateful to the Science Research Council (B/RG/33539, W. M. E. and D. A. J.) and to the Natural Environment Research Council (research studentship, R. J. K.) for the financial support of this work. We thank the Director of N. V. Leidsche Duinwater Maatschappij for permission to work on the dunes. It is a pleasure to acknowledge the continued help and interest of Dr Jan Wieffering, particularly over the obtaining of maps and permits.

\section{REFERENGES}

CRAWFORD-SIDEBOTHAM, $\Upsilon$. J. 1972. The role of slugs and snails in the maintenance of the cyanogenesis polymorphism of Lotus corniculatus and Trifolium repens. Heredity, 28, 405-411. 
Foulds, W., AND Grime, J. P. 1972. The influence of soil moisture on the frequency of cyanogenic plants in populations of Trifolium repens and Lotus comiculatus. Heredity, $28,143-146$.

GILlmam, M. E. 1955. Ecology of the Pembrokeshire Islands. III. The effect of grazing on the vegetation. 7. Ecol., 43, 172-206.

HUANG, D. s. 1970. Regression and econometric methods. John Wiley and Sons Inc., New York. JoNEs, D. A. 1962. Selective eating of the acyanogenic forms of the plant Lotus corniculatus L. by various animals. Nature, 193, 1109-1110.

JONES, D. A. 1966. On the polymorphism of cyanogenesis in Lotus corniculatus L. I. Selection by animals. Can. 7. Genet. Cytol., 8, 556-567.

Jones, D. A. 1970 . On the polymorphism of cyanogenesis in Lotus corniculatus L. III. Some aspects of selection. Heredity, 25, 633-641.

JONEs, D. A. 1972. On the polymorphism of cyanogenesis in Lotus corniculatus L. IV. The Netherlands. Genetica, 43, 394-406.

LAMBERT, J. M., AND Williams, w. T. 1962. Multivariate methods in plant ecology. IV. Nodal analysis. 7. Ecol., 50, 775-302.

SHIMWELl, D. w. 1971. Description and Classification of Vegetation. Sidgwick and Jackson, London. 